\title{
Chemical speciation of Ag in galena by EPR spectroscopy
}

\section{Pilario Costagliola, ${ }^{1}$ Francesco Di Benedetto,${ }^{1, *}$ Marco Benvenuti, ${ }^{1}$ Gian Piero Bernardini, ${ }^{1}$ Curzio Cipriani, ${ }^{2}$ Pierfranco F. Lattanzi, ${ }^{3}$ And Maurizio Romanelli ${ }^{4}$}

\author{
${ }^{1}$ Dipartimento di Scienze della Terra, Università di Firenze, Italy \\ ${ }^{2}$ Museo di Storia Naturale, Università di Firenze, Italy \\ ${ }^{3}$ Dipartimento di Scienze della Terra, Università di Cagliari, Italy \\ ${ }^{4}$ Dipartimento di Chimica, Università di Firenze, Italy
}

\begin{abstract}
Electron paramagnetic resonance (EPR) spectroscopy has been used to study the valence state of silver in "argentiferous" galena samples from the Apuane Alps (Tuscany, Italy) mining district. This method was used to reveal primary metallic silver $\left(\mathrm{Ag}^{0}\right)$ in galena. Both thermodynamic data and experimental studies suggest that galena and native silver can stably coexist, but have not been reported as a primary (hypogene) assemblage in natural samples. EPR spectroscopy proved to be a suitable tool to solve this problem, because this technique is capable of detecting paramagnetic species down to the ppb level, even in a highly absorbent matrix such as galena.

A detailed SEM-EDS investigation could not detect metallic silver (or gold) in galena samples, but did reveal small (few micrometers) inclusions of Ag-bearing phases, in which silver has a formal valence of +1 . On the other hand, EPR spectra indicated the presence in galena of pairs and clusters of elemental silver atoms, which may be associated with pairs of metallic gold, or with silver-gold hetero-atomic pairs. Therefore, SEM/EDS and EPR are complementary techniques, revealing the presence of both $\mathrm{Ag}^{+}$and $\mathrm{Ag}^{0}$.

$\operatorname{The} \operatorname{Ag}(\mathrm{Au})$ metallic species were apparently deposited on the galena surface during its growth from mineralizing fluids. Their scarcity, and the presence of larger amounts of $\mathrm{Ag}^{1+}$ phases, suggest that the assemblage galena-metallic silver was stable only under peculiar physical and chemical conditions. The formation of $\mathrm{Ag}^{0}$ was presumably linked to local and rare chemical fluctuations of the hydrothermal environment, characterized by low activities of $\mathrm{S}, \mathrm{Sb}, \mathrm{Bi}(\mathrm{Cu} .$.$) and high activity of \mathrm{Ag}$ in the fluids. The occurrence of both homo- and hetero-atomic pairs suggests either different kinetics of pair formation, or possible fluctuations in the composition of the hydrothermal fluids, which alternatively carried $\mathrm{Ag}$ or Au species, or both.
\end{abstract}

